\title{
A “APERCEPÇÃO TRANSCENDENTAL" KANTIANA FRENTE AO EU PURO FICHTEANO DO CRITICISMO AO IDEALISMO ALEMÃO
}

Matheus dos Reis Gomes ${ }^{1}$

\begin{abstract}
RESUMO: O presente trabalho, em síntese, analisa as concepções kantianas acerca da epistemologia e, mais precisamente, da constituição da tese sobre o criticismo e, da formulação da estrutura conceitual da "apercepção transcendental", isto é, do Eu penso na sua filosofia. Frente às problemáticas da filosofia moderna, relacionar o criticismo kantiano ao advento do idealismo alemão requer trazer à tona um dos filósofos principais, tanto do idealismo em si, mas um continuador, por excelência, do neokantismo, a saber: Johann Gottlieb Fichte (1762-1814). Portanto, para esta abordagem tende-a transformação da filosofia kantiana sob a leitura de Fichte acerca da reformulação do conceito da "apercepção transcendental" (Eu penso), para a formulação do Eu puro em Fichte.
\end{abstract}

Palavras-chave: Criticismo; Idealismo alemão; Kant; Fichte.

\section{THE TRANSCENDENTAL APPERCEPTION KANTIANS FRONT OF THE "PURE I" FICHTEAN} FROM CRITICISM TO GERMAN IDEALISM

\begin{abstract}
The present work consists, in summary, to analyze the Kantian conceptions about the epistemology and, more precisely, of the constitution of the thesis on the criticism and, not less important, of the formulation of the conceptual structure "transcendental apperception", that is, of the "I think" in philosophy. Front to the problems of the modern philosophy, to relate the criticism in Kant to the coming of the German idealism requests to bring to the surface one of the main philosophers, so much of the idealism in itself, but a successor, par excellence, of the neokantians, to know: Johann Gottlieb Fichte (1762 -1814). Therefore, for this approach tends the transformation of the philosophy the Kant under the reading of Fichte concerning the reformulation of the concept of the "transcendental apperception, in other words, of the me leaning, for the formulation of the "pure I" in Fichte.
\end{abstract}

Keywords: Criticism; German idealism, Kant; Fichte.

\section{INTRODUÇÃO}

\footnotetext{
${ }^{1}$ Bacharel em Ciências Humanas - Universidade Federal de Juiz de Fora - UFJF. Pós-graduado em Ciência da Religião - Faculdade Única de Ipatinga (FUNIP). Graduando em Filosofia pela Universidade Federal de Juiz de Fora - UFJF. 
No advento da idade moderna, nomes como Descartes (1596-1650), Spinoza (1632-1677) e Leibniz (1646-1716) são enveredados pelo caminho das concepções aristotélicas, e possuem no desenvolvimento das concepções precípuas e singulares, atribuições que regeram, principalmente em suas épocas, conceitos que transformaram a "mecânica" que a filosofia seguia. Mal comparando aos sistemas de engrenagens, tais autores fomentaram mudanças do modo em que a filosofia estava sendo regida na idade medieval, agrupando nas suas tabulações conceitos distintos das filosofias gregas frente às concepções teológicas; basta remeter às figuras de St. Agostinho e Platão e, não menos importante, à St. Tomás de Aquino e Aristóteles. Descartes e Spinoza mudaram a forma de encarar o movimento da filosofia. Os sistemas apresentados por esses autores revelam, de maneira sintética, uma mesma fundamentação de conhecimento do objeto no mundo, algo que passa do sujeito, do indivíduo em si, onde, posteriormente, surgiu a expressão clássica formulada pelos alemães de Weltanschauung, ou seja, uma visão de mundo (HESSEN, 2000, p.7).

Com Immanuel Kant (1724-1804), a filosofia ressurgirá. Nas palavras de Hessen (2000), com o nascimento da filosofia kantiana, a estrita filosofia "reviverá"(p.7). A filosofia assumiu, novamente, e trouxe para o cerne do pensamento, a importância da autorreflexão, onde a ótica das concepções do sujeito se voltaram novamente para si e, também, para o "espírito" do indivíduo. Tal filosofia surgiu, de maneira clara e evidente, como uma teoria do conhecimento, uma epistemologia "[...] como fundamentação crítica do conhecimento" (HESSEN, 2000, p.7). Neste ínterim, esta questão remete àquilo que constituiu o próprio movimento da história da filosofia. A fundamentação crítica do conhecimento não se limitou apenas no domínio teórico formal, conceitual e filosófico em si, mas vai além, perpassa no horizonte da objetividade onde se encontra a "[...] a fundamentação crítica dos valores em sua totalidade” (HESSEN, 2000, p.7). Das obras como Crítica da razão pura (1781), Crítica da razão prática (1788)e Crítica do juízo (1790), surgem, como dito acima, um deslocamento de eixos, ou seja, uma mudança da Weltanschauung para uma reflexão acerca de si, ou melhor, uma autorreflexão acerca do espírito.

$\mathrm{Na}$ concepção acerca do movimento da filosofia e das instâncias da teologia no período histórico, filosófico e teológico do "idealismo alemão", a figura de Johann Gottlieb Fichte (1762-1814) se tornou um dos grandes pilares da filosofia performática 
moderna e, talvez, o principal nome dentro do invólucro que perscruta o limiar da academia científica, a saber: neokantismo. É preciso destacar que o período da filosofia moderna surge, posteriormente, ao longo do período da filosofia medieval. Desta forma, concepções desenvolvidas durante a época medieval, se tornaram, não obstante, conceitos basilares, problemas fundamentais, tanto do ambiente da grande área da filosofia, mas também, da teologia, sendo um dos principais temas para Fichte a respeito do problema do conceito e da figura "divina" de Deus, sintetizando-a sua ótica frente ao homem e também à realidade.

Portanto, existem neste trabalho três objetivos específicos que serão elencados ao longo de todo texto. $\mathrm{O}$ primeiro se dirige à conceituação da teoria do conhecimento (epistemologia) de Kant à inserção da problemática a respeito da "apercepção transcendental" na obra A crítica da Razão Pura. O segundo é apresentar a figura de Fichte e a sua leitura de Kant na construção do idealismo, configurado na síntese kantiana das críticas, a respeito do Eu puro. O terceiro é oferecer a descrição entre a constituição do Eu transcendental kantiano frente à realidade do "Eu que se põe a si mesmo" fichtiano.

\section{O CRITICISMO DE IMMANUEL KANT E O EU TRANSCENDENTAL}

Para Hessen (2000), em uma análise última, teorias como o subjetivismo, relativismo e até o pragmatismo são, em tese, configurados em uma concepção cética, ou seja, tais teorias epistemológicas são uma forma, das suas variadas perspectivas, de ceticismo. A grosso modo, a existência de extremos pontos acerca da possibilidade conhecimento de um determinado objeto configura preposições a ser tomadas sobre o interesse condicional de estarem tanto de um lado, localizada o dogmatismo, mas também, existe o seu outro ponto extremo, o ceticismo. Tendo em vista a complexidade do conhecimento que a discussão que o presente trabalho suscita é possível trazer à tona perguntas que, muito provavelmente, os filósofos - principalmente Kant - se perguntaram: Existe alguma via intermediária entre dois extremos? Isto é, haveria a possibilidade de conhecer um objeto sem a adesão do dogmatismo e do ceticismo extremo? 
Kant, portanto, se dirigiu a este grande problema que assola, talvez, uma quantidade expressiva de filósofos modernos. Mas o filósofo alemão propôs uma outra via. Um caminho do "meio" entre o ceticismo e o dogmatismo. O dogmatismo possui "uma confiança cega na capacidade da razão humana" (HESSEN, 2000, p.43) e o ceticismo por estrutura "a desconfiança adquirida, sem crítica prévia, contra a razão humana" (HESSEN, 2000, p.43). Este caminho é o que os filósofos chamaram de criticismo. O criticismo:

[...] compartilha com o dogmatismo uma confiança axiomática na razão humana; está convencido de que o conhecimento é possível e de que a verdade existe. Enquanto, porém, essa confiança induz o dogmatismo a aceitar de modo, por assim dizer, inconsciente toda afirmação da razão humana e a não reconhecer nenhum limite para a capacidade humana de conhecimento, o criticismo, aproximando-se do ceticismo, junta à confiança no conhecimento humano em geral uma desconfiança com relação a qualquer conhecimento determinado. Ele põe à prova toda afirmação da razão humana e nada aceita inconscientemente. Por toda parte pergunta sobre os fundamentos, e reclama da razão humana uma prestação de contas. Seu comportamento não é nem cético nem dogmático, mas criticamente inquisidor - um meio termo entre a temeridade-dogmática e o desespero cético (HESSEN, 2000, p.43).

A assertiva que o verdadeiro fundador do criticismo é, portanto, Kant. Assim, antes de chegar a teoria do criticismo, Kant passou pelo dogmatismo e, também, não menos importante para o seu pensamento, pelo ceticismo. Como dito acima, tanto o dogmatismo quanto o ceticismo estão em pontos distantes um do outro, mas, para o filósofo as duas teorias podem se configurar como unilaterais em si, e o criticismo tende a superar tais unilateralidades apresentadas tanto pelo dogmatismo tanto pelo ceticismo. Para Hessen (2000), este é o único método que corresponde à nítida possibilidade de busca pelo conhecimento; "o criticismo é o único ponto de vista correto" (HESSEN, 2000, p.43).

Para isso, a possibilidade de conhecimento tende a passar frente à teoria do criticismo, justamente por colocar tal objeto a se conhecer em um dos extremos. Mas para isso, Kant olha para a própria capacidade de entendimento, e isto se assinala na perspectiva do olhar kantiano na sua "revolução copernicana", por onde o fundamento de todo objeto estaria de maneira integral no sujeito. A dada "revolução copernicana" que Kant realiza com sua obra, se traduz, que o fundamento de um objeto específico 
estaria presente no sujeito, e não no objeto. Mas se o criticismo é a melhor forma, o único ponto de vista do conhecimento, qual então seria o fundamento supremo, isto é, “o princípio supremo do conhecimento"? Kant então propõe que este seria a “apercepção transcendental”, ou seja, o Eu penso.

Assim, Kant introduz uma figura teórica que designa a "apercepção transcendental" junto à figura do "Eu penso". O Eu penso está ligado às doze categorias: 1) Quantidade: Unidade, Pluralidade e Totalidade; 2) Qualidade: Realidade, Negação e Limitação; 3) Relação: Substância, Causalidade e Comunidade; 4) Modalidade: Possibilidade, Existência e Necessidade, onde é necessário e evidente que elas se apresentem como uma unidade, ou seja, uma unidade suprema que designa a consciência ou a autoconsciência, onde Kant a intitula de "Eu penso" (REALE \& ANTISERI, 2005). Portanto, o "Eu penso" acompanha, obrigatoriamente, toda as formas de representações, permanecendo idêntico, igual à sua forma. Ou seja, se o $E u$ acompanhar toda a representação e, por algum motivo, ele se transformasse, mudasse e não se mantivesse idêntico à sua forma original, as variações de representações mudariam e transformariam com as próprias representações. Para Kant (1992):

\begin{abstract}
A unidade analítica da consciência é inerente a todos os conceitos comuns enquanto tais; assim, por exemplo, quando penso o vermelho em geral, tenho a representação de uma qualidade que (enquanto característica) pode encontrar-se noutra parte ou ligada a outras representações; portanto, se mediante uma unidade sintética possível, previamente pensada, posso ter a representação da unidade analítica. Uma representação, que deve pensar-se como sendo comum a coisas diferentes, considera-se I como pertencente a coisas que, fora desta representação, têm ainda em si algo diferente; por conseguinte, tem de ser previamente pensada em unidade sintética com outras representações (ainda que sejam apenas representações possíveis), antes de se poder pensar nela a unidade analítica da consciência que a eleva a um conceptus communis.E, assim, a unidade sintética da apercepção é o ponto mais elevado a que se tem desuspender todo o uso do entendimento, toda a própria lógica e, de acordo com esta, afilosofia transcendental; esta faculdade é o próprio entendimento (Kant, CRP, 1992, B 134 - nota de rodapé). (Grifo nosso).
\end{abstract}

Com essa afirmação, Kant supera as tradições que afirmam que as ações autônomas de cada faculdade do saber se mostraram sem fundamento, sem alguma percepção, obnubiladas. Na organização racional do entendimento, Kant explica conceitualmente a unidade com "[...] a representação Eu penso (Ich denke) com a necessária autoconsciência teorética" (UTTEICH, 2018, p. 98). Para isso devemos 
recordar o que foi dito em alguns parágrafos acima sobre o conhecimento. Para Kant (1992), todo o conhecimento, deve exigir um conceito, mesmo que tal conceito seja obscuro, imperfeito. Este conceito, que pode ser imperfeito, toma uma forma universal, um certo fundamento que quando aplicado servirá, imediatamente, de regra (Kant, CRP, 1992, A 106 - nota de rodapé).

Este fundamento objetiva uma condição transcendental, na medida em que consiste toda a necessidade. Isto é, “[...] deve encontrar-se, portanto, um princípio transcendental da unidade da consciência na síntese do diverso de todas as nossas intuições" (Kant, CRP, 1992, A 106 - nota de rodapé). Estas condições originárias, um princípio transcendental, é tão somente a apercepção transcendental, o Eu penso (Kant, CRP, 1992, A 107 - nota de rodapé).

\section{FICHTE E A CONCEPÇÃO DO EU PURO}

Reale e Antiseri (2005) destacam que a presença da filosofia de Spinoza e também de uma leitura determinista da realidade eram presentes no pensamento de Fichte, tanto na concepção frente à filosofia, mas também, na leitura feita a partir da teologia dogmática. Posteriormente a esse processo de visão de mundo Weltanschauung, e mais precisamente no ano de 1790, Fichte, através de um pedido de um aluno a respeito da obra de Kant, teve então o seu primeiro contato com o filósofo criticista, e a partir daí, em específico com a obra a Crítica da Razão Pura, revela que tal leitura realizou uma profunda transformação nas suas características metodológicas.

Um dos conceitos que Fichte trabalha frente à obra de Kant é a questão do $E u$, e mais precisamente, os elementos expostos da Crítica da Razão Pura,Crítica da RazãoPrática e a Crítica da Faculdade de Julgar. Tal interpretação proporcionou a Fichte uma formulação entre a concepção dos dados expostos pelas obras de Kant e, no fim, transformá-la em um método. A atribuição dos conceitos kantianos por Fichte também gerou em uma reformulação da concepção da "apercepção transcendental". Fichte, de maneira sintética, direcionou a interpretação do Eu penso para o Eupuro. A interpretação acerca do $E u$ a partir de um direcionamento do neokantismo, respalda o princípio de base, a unificação, de maneira aplicada, a síntese entre a tríplice do criticismo apontado por Kant (REALE \& ANTISERI, 2005, p.50). 
Nesta tentativa de unificação das três críticas, propondo assim um único sistema, uma "doutrina da ciência" (nome dado ao seu livro), Fichte utilizou de três grandes autores, onde utilizou tudo "tanto o positivo como o negativo" das teorias; os autores citados para essa formulação são: Karl Leonhard Reinhold (1757-1823), Gottlob Ernst Schulze (1761-1833) e, por fim, Salomon ben Joshua, vulgo Maimon (1753-1800) (REALE \& ANTLSERI, 2005, p.50). Em relação ao filósofo Karl Leonhard Reinhold, Fichte reconhece a atenção que o presente filósofo apontou em reconduzir a filosofia kantiana, com as críticas a um sistema, "um princípio único", tendo em vista a preparação desses "dados" apresentados por Kant à fundamentação da filosofia como ciência. Mas a limitação de Reinhold em realizar a enfatização desse sistema, se desdobrou por não encontrar esse tal "princípio", pois, o princípio da representação se valeria apenas para uma análise sobre a filosofia teórica, e não se dirigia à toda a filosofia (REALE \& ANTISERI, 2005, p.50). A concepção de Fichte sobre Gottlob Ernst Schulze, foi de extrema importância, mas não quanto a de Reinhold. Schulze apresentou a Fichte uma compreensão sobre as críticas céticas, onde expôs o quanto isto era importante; essa crítica veio em relação ao Reinhold, afirmando que era de total insuficiência a ótica de Reinhold, onde era preciso se afastar de tal filósofo para procurar um princípio único. Já em relação ao Maimon, Fichte reconhece na sua obra, a impossibilidade de mostrar a "coisa em si” (REALE \& ANTISERI, 2005, p.50).

Logo, com os auxílios desses autores descritos acima, Fichte apresenta uma novidade: a transformação do Eu penso em Eu puro, que é entendida como uma “intuição pura, que se põe", onde configura o $E u$ com a liberdade plena, onde se está o $\mathrm{Eu}=\mathrm{Eu}$ (REALE \& ANTISERI, 2005, p.50). Para Fichte, o Eu é:

\footnotetext{
O Eu de Fichte é o princípio originário e absoluto de toda a realidade, e se qualifica essencialmente como atividade que antes de tudo põe a si mesma e portanto, põe todas as coisas; desse modo, o Eu é condição incondicionada de si mesmo e da realidade. Na metafísica anterior a Fichte, a atividade, o agir, era sempre considerado consequência do ser (operarisequitur esse), o ser era condição do agir; o idealismo de Fichte inverte, ao contrário, o antigo axioma e afirma que esse sequitur operari: a ação precede o ser, o ser e produto do agir. E, assim, o Eu penso kantiano, que era a estrutura transcendental fundamental do sujeito, torna-se em Fichte atividade, auto-intuição (a intuição intelectual que o próprio Kant considerava impossível para o homem), autoposição da qua1 são deduzidas todas as coisas. O Eu absoluto não é o eu do homem individual, ao qual pertence um eu sempre e em todo caso limitado pelo não-eu (REALE \& ANTISERI, 2005, p.50).
} 


\section{PERSPECTIVAS ACERCA DO EU: ENTRE KANT E FICHTE}

Segundo Utteich (2018), o encontro de Fichte com a obra de Immanuel Kant, principalmente na obra Crítica da Razão Prática (1788), efetiva este "encontro" a não concepção - entendida até o momento - de uma realidade determinista, isto é, a atribuição de uma concepção limitada da faculdade autônoma humana frente à sua liberdade, onde a figura de Deus pressuporia a criação do mundo, da realidade, segundo as leis. Objetivamente, seriam determinadas a todos os acontecimentos da própria realidade, do mundo e até a liberdade humana, sendo estas supostamente, até então, visadas a própria vontade. Esta "sentença" determinista, articulada dentro dessa perspectiva limitada, gerou em Fichte uma crise "interior", onde tal fato se choca com a figura de Deus em relação a liberdade do sujeito.

Em Kant, a razão não consegue, por mais que se esforce e leve os conceitos a sua última limitação, apresentar uma prova, tanto ontológica, como também cosmológica a respeito da existência efetiva de Deus (KANT, 1992). No plano onde se estreitam as questões da teoria a respeito das questões racionais (metafísicas), isto se torna, dentro do pensamento de Kant, inviável. Desta forma, salienta Utteich (2018), "ele recobra então a tranquilidade da alma e o entusiasmo e alega estar vivendo em um novo mundo após constatar que a liberdade pode ser demonstrada pela razão" (UTTEICH, 2018, p.95).

Para Reale e Antiseri (2005), o contato de Fiche com a obra de Kant proporcionou, de maneira evidente, uma "autêntica revelação" (REALE \& ANTISERI, 2005, p.48). Essa "autêntica revelação" proporcionou um encontro, que estava limitado com o sentido da existência, e proporcionou a retirada de um pensamento extremamente pessimista que estava rondando os pensamentos de Fichte. Mas se Kant transformou, segundo ele, o próprio desdobramento da filosofia e também da sua própria compreensão da filosofia, Fichte quis ir além da obra kantiana, ir ao horizonte que o criticismo kantiano estabelecia. Para Fichte, Kant estabeleceu com maestria os dados, os conceitos para construir um sistema, mas, não compreendia, o "porquê" da não concretização do sistema, (REALE \& ANTISERI, 2005). Esse sistema constitui, primeiramente, em estabelecer um método que abarcaria o sistema filosófico 
correspondente à liberdade do sujeito (FICHTE, 1984, p.8). Esse sistema estaria "condicionado" a transformação da filosofia em uma autêntica ciência, um sistema que "[...] brotasse de um princípio primeiro supremo: trata-se da chamada 'doutrina da ciência' (Wissenschaftslehre)" (REALE \& ANTISERI, 2005, p.50).

\begin{abstract}
A filosofia é uma ciência: - nisto todas as descrições da filosofia estão de acordo, assim como estão divididas na determinação do objeto dessa ciência. E se esse desacordo proviesse de que o próprio conceito de ciência, que conferem por unanimidade a filosofia, não tivesse sido totalmente desenvolvido? E se a determinação desse único atributo, admitido por todos, fosse plenamente suficiente para determinar o conceito da própria filosofia? (FICHTE, 1984, p.39).
\end{abstract}

Sendo Fichte o primeiro continuador, por excelência, da filosofia kantiana, é possível notar o sobressalto e a transformação da filosofia de Fichte na perspectiva ética, filosoficamente abarcada em Kant, assinalando uma ocupação moral "consigo", em vez de inclinar tal reflexão as coisas exteriores (UTTEICH, 2018). Tal constatação apresentada pelo autor, reitera, em Fichte, a característica do método transcendental do conhecimento a priori, explicitado no Prefácio daTradução Portuguesa do livro Crítica da Razão Pura (CRP), onde um determinado conhecimento "que precede a experiência e cujo objeto não nos pode ser dado pela experiência. Um objeto desta ordem será o próprio sujeito, a estrutura do sujeito, e é esta estrutura que torna possível a experiência (KANT, 2001, p.12). O conceito e o fator a priori "[...] não provêm, segundo ele, da experiência, mas do pensamento da razão. A razão leva, por assim dizer, as formas $a$ priori até o imaterial da experiência e determina, destarte, os objetos do conhecimento" (HESSEN, 2000, p.63). A filosofia de Kant, possui por agregação os conceitos desenvolvidos de filosofias que estariam já consolidadas, tanto na ótica racionalista de Leibniz e Wolff, mas também do empirismo desenvolvido por Locke e Hume. Esta “junção" das duas visões acerca da epistemologia, configura o assentamento que o conhecimento, ou melhor, que o material do conhecimento provém da experiência, enquanto a forma - do conhecimento - viria do pensamento (HESSEN, 2000, p.63). Para o autor:

Com o material, tem-se em vista as sensações. Elas são completamente desprovidas de determinação e de ordem, apresentam-se como um puro caos. Nosso pensamento produz ordem nesse caos na medida em que conecta os 
conteúdos sensíveis uns aos outros e faz com que eles se relacionem. Isso ocorre por meio das formas de intuição e do pensamento. Espaço e tempo sãos as formas de intuição. A consciência cognoscente introduz ordem do tumulto das sensações na medida em que as ordena espacial e temporalmente na simultaneidade ou na sucessão. Em seguida, com a ajuda das formas de pensamento (doze, segundo Kant), introduz uma outra conexão entre os conteúdos perceptivos (HESSEN, 2000, p.63).

Fichte agrega à filosofia de Kant o fato da apreensão do conceito de a priori, como dito anteriormente, fato este interpretado que a própria razão do indivíduo possui tal concepção, por onde tal interpretação "[...] trata-se de alcançar o estágio em que tudo, a filosofia inteira, seja colaborar a favor da perspectiva prática da razão, a mais adequada para lidar com os domínios do conhecimento teorético (ciências particulares)" (UTTEICH, 2018, p.96) ${ }^{2}$.

\section{CONCLUSÃO}

O presente artigo buscou responder que o $E u$ em Fichte, constitui, basicamente, uma designação que corresponde o princípio originário em si, absoluto em toda sua completude em relação a toda a realidade de existência. Além disso, destacou-se que o $E u$ fichteano se qualifica como uma atividade que, antes de sua "expressão", se põe essencialmente em si mesma, onde todas as coisas são postas antes de tudo no sob a condição do $E u$. Diferentemente de Kant acerca do $E u$ transcendental, o $E u$ para Fichte é, sem dúvida, uma "condição incondicionada de si mesmo e da realidade" (REALE \& ANTISERI, p.50). Como pudemos analisar, a ótica da filosofia de Fichte para os períodos anteriores da filosofia moderna, principalmente em relação a metafísica, o agir na filosofia era considerado, essencialmente, uma consequência do ser, isto é, em outras palavras, o agir era considerado uma consequência do ser, e o ser é, por excelência, o produto do agir (REALE \& ANTISERI, p.50).

De maneira singular, o idealismo de Fichte que possui sua gênese em Berkeley, se desenvolve no neokantismo e se apresenta a uma vertente lógica; assim, tal

\footnotetext{
${ }^{2}$ Para Kant: O Eu penso, ou Apercepção transcendental, e a unidade transcendental originária e suprema da autoconsciência, que é comandada por doze categorias: ela e a autoconsciência que, enquanto produz a representação "Eu penso", constitui a possibilidade do conhecimento a priori que deriva do Eu penso: e o princípio da unidade sintética originária, a própria forma do intelecto (REALE \&ANTISERI, 2005, p. 365).
} 
perspectiva é configurada por um idealismo lógico, ao fato de Fichte expandir "o eu cognoscente no eu absoluto e procurou derivar toda a sua realidade" (HESSEN, 2000, p.84). Portanto, “o Eu penso kantiano, que era a estrutura transcendental fundamental do sujeito, torna-se em Fichte atividade, auto intuição (a intuiçãointelectual que o próprio Kant considerava impossível para o homem), autoposição da qual são deduzidas todas as coisas" (REALE \& ANTISERI, p.50).

\section{REFERÊNCIAS}

FICHTE, Johann G. A doutrina-da-ciência. Seleção de textos. Trad. e Notas de Rubens Rodrigues Torres Filho. - 2ed. - São Paulo: Abril Cultura, 1984.

HESSEN, Johannes. Teoria do Conhecimento. Tradução: João Vergílio Gallerani Cuter. São Paulo: Martins Fontes, 2000.

KANT, Immanuel. Crítica da razão pura. Trad. Manoela P. dos Santos. Lisboa: Gulbenkian, 1992.

REALE, G. \& ANTISERI, D. História da filosofia, 5: do romantismo ao empiriocriticismo; [tradução de Ivo Storniolo]. - São Paulo: Paulus, 2005, - (Coleção história da filosofia).

UTTEICH, Luciano C. Fichte e a Radicalização da Revolução Copernicana de Kant. Revista Ética e Filosofia. Número: XXI - Volume I - julho de 2018, p.94129.Disponível

em:<https://eticaefilosofia.ufjf.emnuvens.com.br/eticaefilosofia/article/view116/141>. Acesso em 20 de novembro de 2018. 